\title{
NOTAS SOBRE GOVERNO DO DIREITO, ÉTICA DAS VIRTUDES E DIREITOS HUMANOS
}

\author{
"La ley es como el cuchillo, \\ no corta al que lo maneja" \\ José Hernández, Martín Fierro \\ "[N]ão há leis tão justas eleves, \\ que não necessitem de quem \\ as faça executar e guardar" \\ Antônio Vieira, Voto sobre as dúvidas dos moradores de S. Paulo acerca da \\ administração dos índios (12 de julho de 1694)
}

\section{Carlos Ignacio Massini Correas ${ }^{1}$ \\ Frederico Bonaldo ${ }^{2}$}

\section{Resumo}

Neste trabalho, resumem-se a significação e as origens da ideia de governo do direito, distinguindo o seu sentido clássico do iluminista e vinculando-a - o que se mostra necessário - com a ética das virtudes e com a noção de direitos humanos. Desse modo, a fórmula completa do bem comum - da justiça geral - radicará na supremacia da lei, que é a da razão prático-ética, somada à presença das virtudes morais nos governantes e nos governados, bem como ao respeito pelos direitos naturais do homem.

Palavras-chave: governo do direito - ética das virtudes - direitos humanos.

\section{A QUESTÃO A SER TRATADA E AS SUAS RAÍZES}

Desde sempre, um dos problemas centrais da filosofia política e jurídica é o de evitar o exercício arbitrário e discricionário do poder político por parte dos governantes; isto é, o de impedir o perigo da tirania ${ }^{3}$. Ao longo da história, são muitos os artifícios pensados para afugentar este flagelo; entre eles, o mais persistente e contínuo no tempo é o denominado "governo do direito", "império da lei" ou - nas versões mais oitocentistas - "estado de direito”.

\footnotetext{
${ }^{1}$ Professor Titular Ordinário de Filosofia Jurídica e de Ética na Universidad de Mendoza (Argentina). Diretor do Instituto de Filosofia Prática e Humanidades Jurídicas na mesma instituição. Doutor em Direito pela Universidad de Mendoza. Doutor em Filosofia pela Universidad Nacional de Cuyo (Argentina).E-mail: carlos.massini@um.edu.ar

${ }^{2}$ Professor Assistente de Metodologia e Lógica Jurídica na PUC-SP. Doutorando em Filosofia do Direito na PUC-SP. E-mail: fredericobonaldo@gmail.com

${ }^{3}$ Sobre a noção de “tirania”, veja-se STRAUSS, Leo. Sobre la tiranía. Trad. L. Rodríguez Duplá. Madrid: Encuentro, 2005. vol.09, nº. 01, Rio de Janeiro, 2016.pp. 586-603 
Para vários autores contemporâneos, especialmente para os que participam das ideias liberais mais ativamente ${ }^{4}$, a ideia do governo do direito tem as suas raízes principais no Iluminismo e as suas concreções mais adequadas nas sociedades que seguiram a linha do constitucionalismo racional-normativo próprio da revolução francesa ${ }^{5}$. Segundo esta versão, a sujeição do poder político à lei tem como finalidade principal resguardar a autonomia dos indivíduos, a fim de que possam elaborar os seus planos de vida; e os seus instrumentos centrais são as declarações de direitos e a divisão do poder do Estado em três órgãos diferentes, reciprocamente contrabalanceados e limitados. Em suma, trata-se de uma versão precipuamente individualista e procedimental do governo do direito.

Embora esta apresentação liberal tenha sido a que mais se difundiu nos últimos dois séculos e a que é considerada como a opção default sempre que se menciona a ideia do governo das leis, ela não é a primeira historicamente e muito menos a única na história do pensamento. Com efeito, muitos séculos antes que Montesquieu redigisse De l'esprit des lois, essa ideia fora proposta por pensadores tão dessemelhantes dos iluministas como Platão e Aristóteles. O primeiro deles, na sua obra máxima da maturidade, As leis, escreveu inequivocamente:

Aos que agora se dizem governantes, chamei-os servidores das leis, não para introduzir novos nomes, mas porque creio que, mais que qualquer outra coisa, é isso o que determina a salvação ou perdição da cidade; pois naquela [cidade] onde a lei possui a condição de súdita sem força, já vejo a destruição vir sobre ela; e naquela outra onde a lei é senhora dos governantes e onde os governantes são servos da lei, vejo realizada a sua salvação e todos os bens que os deuses outorgam às cidades ${ }^{6}$.

Por sua vez, o Estagirita aborda a questão tanto na Retórica como na Ética a Nicômaco e na Política. Nesta última, após um desenvolvimento extenso, conclui que "é melhor que a lei governe em vez de qualquer dos homens" ${ }^{7}$, ainda que se trate do melhor deles. Esta doutrina tornou-se canônica para todos os estudos posteriores sobre o governo do direito ${ }^{8}$; ela pode resumir-se dizendo o seguinte:

[Para Aristóteles,] em geral, o governo segundo a soberania da lei é tal que somente os estados que são governados-por-lei podem reclamar a sua bondade de algum modo. Pelo contrário, os estados em que "os homens governam, e não as leis" - para inverter a expressão madisoniana - nunca estão longe da tirania e, como foi dito, às vezes, são considerados como sem-constituição?

\footnotetext{
${ }^{4}$ Veja-se VANOSSI, Jorge. Estado de Derecho. Buenos Aires: Astrea, 2008, p. 24 e passim.

${ }^{5}$ Cf. GARCÍA PELAYO, Manuel. Derecho Constitucional Comparado. Madrid: Revista de Occidente, 1964, p. 34-41.

${ }^{6}$ PLATÓN. Las leyes, 715 c-e. Cita-se de acordo com a versão de J. M. Pabón e M. Fernández-Galiano (Madrid: Instituto de Estudios Políticos, 1960). Neste ponto, veja-se LETWIN, Robin. On the history of the idea of law. Cambridge: Cambridge University Press, 2008, p. 9-20.

${ }^{7}$ ARISTÓTELES. Política, III, 16, 1187 a 18 et seq. Neste ponto, veja-se KRAUT, Richard. Aristotle: political philosophy. Oxford: Oxford University Press, 2002, p. 111 et seq.

${ }^{8}$ Veja-se CASTAÑO, Sergio Raúl. Brève analyse de l'empire de la loi chez Aristote. Archiv für Rechts-und Sozialphilosophie, vol. 83-4, Stuttgart, 1997, p. 548-554.

${ }^{9}$ JOHNSON, Curtis N. Aristotle's theory of the state. London: MacMillan, 1990, p. 69. _vol.09, n. 01, Rio de Janeiro, 2016. pp. 586-603 
No período romano, a figura de Cícero destaca-se neste ponto. Em várias passagens de $A$ república e de As leis, ele defende a doutrina do governo das leis acima dos magistrados, que, se não se submetem ao direito, transformam-se em déspotas, isto é, "[n]a criatura mais asquerosa e repelente que se possa imaginar" ${ }^{10}$. Em As leis, o Reitor sustenta que "uma vez que os magistrados estão sujeitos às leis, o povo está sujeito aos magistrados. De fato, é verdadeiro dizer que o magistrado é uma lei falante e que a lei é um magistrado silencioso" ${ }^{11}$. Como diz Brian Tamanaha, é certo que, "para Cícero, o status supremo das leis gira em torno da sua consistência com a lei natural" ${ }^{2}$, questão esta que aparece de modo bastante difuso e até mesmo ambíguo no pensamento do ateniense e do macedônio.

Mas tal como sustenta o recém-citado Tamanaha, a tradição do governo do direito só se solidificou na Idade Média, através de um processo lento, complexo e em parte espontâneo, sem uma fonte única nem um ponto de partida precisamente determinável ${ }^{13}$. Ao que parece, o primeiro teórico do direito que desenvolveu e formulou essa ideia foi um clérigo inglês chamado Henry de Bracton, quase contemporâneo de Tomás de Aquino. Na sua obra monumental On the Laws and Customs of England, este chanceler da catedral de Exeter e membro da Corte do Rei (King’s Court) escreveu que o rei devia:

Temperar o seu poder por meio da lei, que é a rédea do poder; viver de acordo com as leis, porque a lei da humanidade decretou que o legislador está obrigado pelas suas próprias leis [...]. Nada é mais ajustado para um soberano que viver segundo as leis, nem há maior soberania que a de governar conforme a lei [ ... ], porque é a lei que o faz rei ${ }^{14}$.

Segundo esta ideia, enfim, o conceito juridicamente mais importante não é o de Estado, mas o de Governo (Government), que engloba, ao menos, as funções executiva e legislativa do Estado. E dentro desta visão, a peculiaridade do Governo é a de estar sempre subordinado ao império do direito, de sorte que a consequência precípua do rule of law - de valor imensurável em termos de uma cultura civilizatória pautada no direito - é a igualdade entre cidadãos e governantes em face das instâncias judicantes ${ }^{15}$.

\footnotetext{
${ }^{10}$ CÍCERO. A república, II, 48.

${ }^{11}$ CÍCERO. As leis, III, 2-3.

${ }^{12}$ TAMANAHA, Brian. On the rule of Law: history, politics, theory. New York: Cambridge University Press, 2009, p. 11.

${ }^{13}$ Ibidem, p. 15.

${ }^{14}$ BRANCTON, Henry. On the laws and customs of England. Vol. III. Cambridge (Mass.): Harvard University Press, 1968, pp. 305-306. Outro clérigo medieval que contribuiu com a elaboração da doutrina do governo do direito foi Isidoro de Sevilha; na sua conhecida obra Etimologias, este autor espanhol afirmou que a lei deve ser "honesta, justa, possível, conforme a natureza, consoante com os costumes do país, apropriada ao lugar e às circunstâncias temporais, necessária, útil, clara [... ], não ditada em benefício particular, mas em proveito do bem comum dos cidadãos" (ISIDORO DE SEVILLA. Etimologías, II, 10. Cita-se de acordo com a edição crítica bilíngue de J. Oroz Reta e M. A. Marcos Casquero (Madrid: BAC, 1982, t. I, p. 375)).

${ }^{15}$ Cf. D’AGOSTINO, Francesco. Lo Stato di diritto: dimensioni e problemi. In: IDEM. Filosofia del diritto. 3 a ed. ampliata. Torino: Giappicchelli, 2000, p. 190.
} 


\section{TOMÁS DE AQUINO E O RULE OF LAW}

Enquanto isso, do outro lado do Canal da Mancha, Tomás de Aquino elaborava uma doutrina completa sobre o tema, que, embora se encontre dispersa em vários lugares das suas obras, compõe um todo sistemático de valor especial ${ }^{16}$. O Aquinate trata desta questão principalmente na Prima Secundae da Summa Theologiae, nas questões 95 e 96, que se referem, respectivamente, à lei humana e ao poder das leis humanas. Ali, sustenta as seguintes teses a respeito do governo do direito:

1. A autoridade política encontra-se sujeita ao poder das leis humanas quanto à sua vis directiva, isto é, no tocante à autoridade moral delas, mas não quanto à sua vis coactiva, ou seja, a capacidade fática de que sejam impostas pela força ${ }^{17}$;

2. No fim das contas, a sujeição dos governantes à lei positiva justifica-se no fato de esta última derivar da lei natural, de maneira que o fundamento do governo do direito finca-se radicalmente na lei natural jurídica ou direito natural ${ }^{18}$;

3. O governo da lei sobre a autoridade política abarca não apenas certos aspectos formais detalhados pelo Aquinate, mas também a ordenação constitutiva das normas jurídicas ao bem comum político; vale dizer: a sua concepção abarca também - e principalmente - aspectos de caráter substantivo ou de conteúdo ${ }^{19}$;

\footnotetext{
${ }^{16}$ Veja-se VIOLA, Francesco. Legge umana, rule of law ed etica delle virtù in Tommaso d'Aquino. In: MANGINI, Michele; VIOLA, Francesco. Diritto naturale e liberalismo: dialogo o conflitto? Torino: Giappicchelli, 2009, p. $11-14$ e passim.

${ }^{17}$ TOMÁS DE AQUINO. Summa theologiae, I-II, q.96, a. 5, ad 3. Como é sabido, nas democracias atuais, isto não se verifica, uma vez que nelas toda atuação dos poderes estatais pode ser alvo da coação das normas que eles mesmos produzem, com o intuito de proteger os governados de eventuais ações abusivas dos governantes, de garantir que os governados possam contar com prestações justas por parte dos governantes e de incitar os governantes a incorporar ao direito valores que vão sendo suscitados na vida social; neste sentido, cf. MORAIS, José Luis Bolzan de. Estado de direito. In: BARRETTO, Vicente de Paulo; CULLETON, Alfredo (Coords.). Dicionário de filosofia política. São Leopoldo: UNISINOS, 2010, p. 186-189.

${ }^{18} \mathrm{Ibidem}, \mathrm{I}-\mathrm{II}$, q. 95 , a. 2. A lei natural jurídica é a parte da lei natural que trata das relações de justiça entre os seres humanos. $\mathrm{O}$ conteúdo da lei natural como um todo ultrapassa essas relações humanas de justiça, pois engloba também as relações humanas atinentes a todas as outras virtudes que a pessoa humana pode adquirir (cf. ibidem, I-II, q. 94, a. 3), como a liberalidade, a misericórdia, a amizade e a caridade. Para efeitos de exposição fidedigna do pensamento jurídico de Tomás de Aquino, é preciso assinalar que - excetuando-se as vezes em que este autor recorre à metonímia e emprega as expressões "lei natural" e "direito natural" como sinônimos - o setor jurídico da lei natural não se confunde com aquilo que o Aquinate chama "direito natural"; com efeito, para Tomás, a lei jurídica (natural ou positiva) caracteriza-se por versar sobre as relações intersubjetivas de maneira hipotética e geral, ao passo que o direito (que é indissociavelmente natural e positivo) é a conduta, a coisa ou a relação justa ajustada, acertada, afinada - entre duas ou mais pessoas dentro de uma relação concreta e individualizada que elas estabeleçam entre si, naquilo que concerne a bens externos a essas pessoas. Assim, a lei natural dá origem - por conclusão dos seus princípios ou por determinação de algo indeterminado - à lei positiva, que, por sua vez, servirá de parâmetro para o ajustamento de uma relação humana intersubjetiva, o qual, necessariamente, compõe-se tanto de fatores advindos da natureza humana e da natureza das coisas especificamente envolvidas nessa relação (isto é o direito natural) como de fatores provenientes de convenções humanas estabelecidas socialmente (isto é o direito positivo). Sobre isto, veja-se GARCÍA-HUIDOBRO, Joaquín. Razón práctica y derecho natural: el iusnaturalismo de Tomás de Aquino. Valparaíso: Edeval, 1993, p. 235-243.

${ }^{19}$ Cf. ibidem, I-II, q. 90 , a. 2.
} 
4. Deste ponto de vista, a tirania pode ser definida como o governo sem lei ou como o governo que não obedece às normas jurídicas ${ }^{20}$;

5. Por fim, a desobediência ou afastamento da lei natural ou das leis divinas (lei divina positiva ou absolutos morais ${ }^{21}$ ) por parte do governo conduz à libertação - no segundo caso, sem exceção - da sujeição dos cidadãos à autoridade política ${ }^{22}$.

Do exposto precedentemente, segue-se com clareza que, na obra do Aquinate, se encontram os elementos de uma concepção completa do rule of law, tanto de forma como de conteúdo; uma concepção que transcende com sobras os limites do seu contexto histórico imediato. Segundo ela, os governantes legítimos - não tirânicos - estão sujeitos às diretivas da legislação positiva da sua comunidade, devendo respeitar as suas exigências constitutivas formais (sanção pela autoridade competente, promulgação ou publicação prévia, praticabilidade, universalidade, igualdade de trato, estabilidade etc.) e os seus requerimentos de conteúdo (especialmente a ordenação ao bem comum, a adequação aos critérios da justiça distributiva e o respeito pelos direitos do cidadão) ${ }^{23}$. Sem dúvida, trata-se de uma concepção claramente jusnaturalista do governo de direito, o que dá razão à conhecida afirmação de Hans Kelsen de que o estado de direito reduzir-se-ia a um simples "preconceito jusnaturalista" ${ }^{24}$. Evidentemente, não se trata de um "preconceito", mas não se pode negar que é integralmente "jusnaturalista".

Contudo, como escreveu Brian Tamanaha ajustadamente, ocorre que:

Nas democracias liberais modernas, a constituição vinculante substitui o papel cumprido anteriormente, durante o período clássico - grego e romano - e medieval, pela lei divina e pela lei natural; ou pelos códigos antigos, pelo direito consuetudinário, na tarefa de prover constriçōes jurídicas aos governantes [...]. Nos nossos dias, uma constituição escrita, as eleições democráticas, os direitos individuais explicitamente articulados, a separação dos poderes e a revisão judicial da legislação são pensados como essenciais para o liberalismo e para o governo do direito ${ }^{25}$.

Desse modo, a lei natural fica claramente num segundo plano, ao passo que os procedimentos e as instituições do estado liberal assumem a primazia.

Por outro lado, assim como tudo aquilo que tem a ver com a práxis humana e com a sua direção ao bem ético, cabe destacar que esta concepção aquiniana do governo do direito tem um caráter analógico, isto é, tem de

\footnotetext{
${ }^{20}$ Cf. ibidem, I-II, q. 95 , a. 4.

${ }^{21}$ A admissão dos absolutos morais implica o reconhecimento da existência de ações humanas intrinsecamente más, isto é, de atos que são eticamente ilícitos sem exceções e em quaisquer circunstâncias. Sobre as condições ético-epistemológicas para a advertência e aceitação dos absolutos morais, cf. ABBÀ, Giuseppe. Costituzione epistemica della filosofia morale: ricerche di filosofia morale - 2. LAS: Roma, 2009, p. 96-97.

${ }^{22}$ Cf. TOMÁS DE AQUINO. Summa theologiae, I-II, q. 96, a. 4.

${ }^{23} \mathrm{Cf}$. ibidem, loc. cit.

${ }^{24}$ KELSEN, Hans. Teoría pura del derecho. 8a ed. Trad. R. Vernengo. México: Porrúa, 1995, p. 320.

${ }^{25}$ TAMANAHA, p. 55-56.
} 
ser aplicada em conformidade com a lógica de um analogado principal ou caso central e de vários analogados secundários ou casos periféricos ${ }^{26}$.

A analogia é a "síntese do semelhante e do diferente" ${ }^{27}$. Ilustremo-lo de maneira simples. Pode-se atribuir a propriedade "força" a realidades diversas, como, por exemplo, a um ser vivo, a um argumento e a um remédio. Com efeito, um ser vivo forte é aquele que tem a capacidade de mover algo ou alguém que tenha peso ou que ofereça resistência; um argumento forte é aquele que é apto a convencer ou persuadir; e um remédio forte é aquele que combate uma doença de forma pungente. Nestes três casos, evidentemente, "força" não tem o mesmo significado, e por isto é diferente a depender da realidade da qual é predicada. No entanto, não é absolutamente diferente quando predicada de um ser vivo, de um argumento e de um remédio, pois, em cada uma destas realidades, o atributo "força" designa efetivamente a qualidade de operar uma mudança, de modo que, nestes exemplos, a ideia - e a palavra - "força" é semelhante, proporcional ou análoga. Mas logo se adverte que a "força" de um argumento e a "força" de um remédio derivam da força física de um ser vivo, que, dos três, é o único que pode mover espacialmente um determinado objeto material. Assim, o analogado principal de "força" é a do ser vivo, enquanto que a força de um argumento e a de um remédio são analogados secundários.

De acordo com esta lógica, existe um caso principal e uma significação focal do conceito - e do nome "governo do direito", no qual as notas formais e substantivas mencionadas apresentam-se de um modo pleno e integral, e casos secundários ou significações periféricas, nas quais este conceito - e este nome - se aplica de modo diluído, incompleto, defectivo ou marginal.

Pois bem, tal como Carlos Llano explicou com precisão ${ }^{28}$, no realismo filosófico, os conceitos ou ideias práticas possuem um caráter paradigmático ou modelar; enquanto tais, não se concretizam nas realidades práticas de modo pleno e completo, mas somente de modo incompleto ou defectivo, de modo que esse conceito só pode ser predicado das suas concreções de modo analógico ou extensivo. Dito em outras palavras, na realidade práticojurídica concreta, a ideia de "governo do direito" não se apresenta de modo perfeito e integral, mas apenas imperfeitamente e na medida em que as circunstâncias históricas, sociais, as inclinações e as virtudes - ou os vícios - humanas o permitem.

\section{GOVERNO DO DIREITO E ÉTICA DAS VIRTUDES}

Esta referência às virtudes humanas faz que seja propícia uma consideração acerca das relações entre o governo do direito e a ética das virtudes na sistemática tomista, especialmente a partir da afirmação da afirmação

\footnotetext{
${ }^{26}$ Veja-se MASSINI CORREAS, Carlos Ignacio. Sobre ciencia práctica y prudentia. Aproximaciones desde las ideas de John Finnis. Sapientia, n. 227-228, Buenos Aires, 2010, p. 41-53.

${ }^{27}$ SANTOS, Mário Ferreira dos. Ontologia e cosmologia. São Paulo: Logos, 1957, p. 77.

${ }^{28}$ LLANO, Carlos. Sobre la idea práctica. Pamplona: EUNSA, 2007, passim.
} vol.09, n. 01, Rio de Janeiro, 2016.pp. 586-603 
bastante difundida de que, no caso da ética de Tomás de Aquino, está-se na presença de uma ética de virtudes, ao menos em grande medida ${ }^{29}$. A respeito desta relação, Francesco Viola sustentou que se "olhamos não tanto a lei positiva considerada em si mesma, mas o processo da sua formação e da sua implementação concreta, então a ética das virtudes tende a assumir toda a sua centralidade", de maneira que é necessário "considerar que as boas leis pressupõem certo grau de prática política da ética das virtudes" ${ }^{30}$. Em outras palavras, não basta a realização dos requisitos do rule of law para que se alcance, em concreto, a justiça das leis; é necessária pelo menos certa medida de virtude moral para lográ-la.

E isto é indispensável, uma vez que - tal como o precisou Leonardo Polo - as virtudes cumprem uma função de causalidade eficiente e formal dos atos bons, razão pela qual, sem elas, é muito difícil - se não impossível - não apenas cumprir efetivamente as ações ordenadas ao bem, mas também determinar em que consistem essas ações ${ }^{31}$. Com efeito, no referente às ações humanas - que são a matéria da moral -, os bens cumprem a função de causas finais e as normas cumprem a função de causas exemplares e eficientes - com eficiência deôntica, ainda que remota - dessas ações ${ }^{32}$. Já as virtudes realizam a tarefa própria das causas eficientes próximas e formais. Isto significa que, sem virtudes - especialmente, sem a prudência - os atos bons/justos - que são árduos e complexos - não apenas não se dariam como seria muito difícil determinar, em concreto, em que consiste a bondade/justiça desses atos.

Tudo isto é confirmado pela experiência cotidiana da práxis jurídica e política, uma vez que as meras fórmulas legais, privadas da virtude de quem as formula e as aplica, não oferecem garantias de retidão no nível das condutas e das soluções concretas ${ }^{33}$. Para que as normas sejam efetivamente diretivas da conduta humana, é preciso que a sua redação, formulação e posterior aplicação prudente aos casos concretos estejam imbuídas de uma vontade reta, isto é, da vontade virtuosa dos operadores jurídicos. Do contrário, ou seja, quando as leis são boas, porém redigidas, postas em funcionamento e concretamente aplicadas por bandos de delinquentes foragidos, só podem conduzir à frustração, à desgraça e ao desvario das coletividades a que se destinam.

Os atuais defensores da virtue jurisprudence - como Lawrence Solum e Colin Farrelly ${ }^{34}$, que a denominam concepção aretaica do direito ${ }^{35}$ - partem da premissa de que o fim próprio das realidades jurídicas é

\footnotetext{
${ }^{29}$ Sobre esta doutrina, veja-se ABBÀ, Giuseppe. Quale impostazione per la filosofia morale?: ricerche di filosofia morale - 1. Roma: LAS, 1996, p. 42 e passim; PIEPER, Joseph. Las virtudes fundamentales. Madrid - Bogotá: Rialp - Quinto Centenario, 1998, p. 12; PORTER, Jean. The recovery of virtue: the relevance of Aquinas for christian ethics. London: SPCK, 1990, p. 100 et seq.

${ }^{30}$ VIOLA, op. cit., p. 61-63.

${ }^{31}$ Cf. POLO, Leonardo. Lecciones de ética. Pamplona: EUNSA, 2013, p. 160. Algumas páginas antes, este autor põe em evidência que uma ética completa tem de ser, ao mesmo tempo, embora em dimensões diferentes, de bens, de normas e de virtudes (p. 137).

${ }^{32}$ Veja-se MASSINI CORREAS, Carlos Ignacio. Filosofía del derecho: tomo I - El derecho, los derechos humanos y el derecho natural. Buenos Aires: LexisNexis - Abeledo Perrot, 2005, p. 59-62.

${ }^{33}$ Veja-se TOMÁS DE AQUINO. Quaestio disputata de virtutibus in communi, a. 1, respondeo (cita-se conforme a tradução de Laura Corso de Estrada, Pamplona, EUNSA, 2000, pp. 75 et seq.).

${ }^{34}$ SOLUM, Lawrence B.; FARRELLY, Colin (Eds.). Virtue jurisprudence. New York: Palgrave-MacMillan, 2011. vol.09, n. 01, Rio de Janeiro, 2016. pp. 586-603 
a promoção da perfeição humana em comunidade, isto é, tornar possível que os seres humanos tenham vidas excelentes e bem realizadas. Para o alcance deste objetivo e a obtenção de uma justiça excelente:

Requer-se a seleção de juízes que possuam as virtudes judiciais: coragem cívica, temperamento jurídico, inteligência prática, sabedoria e, sobretudo, justiça. Estas respostas às questões práticas fundamentais podem unificar-se numa só tese: os conceitos fundamentais da filosofia jurídica não são o bem-estar, a eficiência, a autonomia ou a igualdade; as noções fundamentais da teoria jurídica têm de ser a virtude e a excelência humana ${ }^{36}$.

$\mathrm{Na}$ verdade, de acordo com a sistemática do Aquinate, estas noções fundamentais têm de ser as dimensões centrais do bem humano, os princípios e as normas jurídicas, e as virtudes, em especial as virtudes da justiça e da prudência. Sobre este ponto, John Finnis escreveu:

O Aquinate rejeita esse contraste [entre normas e virtudes] e outorga preeminência sistemática tanto aos standards - como os princípios e as normas - como às virtudes. Com efeito, sustenta que ambos os conceitos definem-se na sua relação recíproca [interdefined] ${ }^{37}$.

Além disto, como já foi visto, não apenas se interdefinem, mas são as virtudes que tornam operativas as normas e os princípios, ao conferir-lhes a atualidade prática, sem a qual careceriam de sentido normativo.

Isto foi explicitado por Giuseppe Abbà num livro de especial valor, intitulado precisamente Lex et virtus. Ali, o filósofo italiano põe em evidência que, para o Aquinate, as leis - especialmente as leis positivas - têm uma função limitada na tarefa de geração da conduta moral. Escreve Abbà:

Do fato de a lei ser uma norma coletiva derivam os seus limites e a sua função na conduta moral. Ela aproxima-se da conduta humana a partir do exterior, ao modo de uma instrução, que o indivíduo deve ter em conta. Ela é necessariamente geral e não pode regular todas as situações singulares; portanto, ela não é suficiente para regular a conduta individual ${ }^{38}$.

Por isto, para este autor, "na medida em que o indivíduo, instruído pela lei, vê o bem humano ou divino naquilo que a lei ordena e o realiza, não tanto porque é o que a lei manda, mas porque é o bem, as virtudes geramse e aumentam nele" ${ }^{39}$. E haveria que acrescentar: virtudes que são o princípio interno do agir e, enquanto tais, os determinadores últimos da ação humana concreta.

Neste sentido mesmo sentido, Robert P. George assevera acertada e sinteticamente:

As leis não podem tornar os homens melhores. Só os homens podem fazê-lo; e podem fazêlo apenas ao escolherem livremente realizar aquilo que é moralmente correto por causa da razão correta. As leis podem ordenar uma conformidade externa com as regras morais, mas não podem compelir os atos internos da razão e da vontade, que são os que fazem que um ato externamente conforme aos requerimentos da moralidade seja um ato moral ${ }^{40}$.

\footnotetext{
35 "Aretaica" diz respeito a virtude, palavra proveniente da latina virtus, cujo um dos significados exprime a ideia de excelência ou perfeição moral. Na Grécia antiga, aquilo que hoje se designa com o termo virtude expressava-se por meio do vocábulo ả petŕ (aretê), cujo sentido original é o de excelência, capacidade, valia. Cf. ROHNHEIMER, Martin. La perspectiva de la moral: fundamentos de la ética filosófica. Madrid: Rialp, 2000, p. 199.

${ }^{36}$ SOLUM, Lawrence B.; FARRELY, Colin. Introduction. In: SOLUM, Lawrence B.; FARRELY, Colin (Eds.), op. cit., p. 2-3

${ }^{37}$ FINNIS, John. Aquinas' moral, political and legal philosophy. In: ZALTA, Edward N. (Ed.). The Stanford encyclopedia of philosophy. Fall 2011 edition. Disponível em: plato.stanford.edu/archives/fall 2011/entries/aquinas-moral-political (acesso em 18 de junho de 2014).

${ }^{38}$ ABBÀ, Giuseppe. Lex et virtus: studi sull'evoluzione della dottrina morale di san Tommaso d'Aquino. Roma: LAS, 1983, p. 269

${ }^{39}$ Ibidem, p. 270.

${ }^{40}$ GEORGE, Robert P. Making men moral: civil liberties and public morality. Oxford: Clarendon Press, 1995, p. 1.
} vol.09, nº. 01, Rio de Janeiro, 2016.pp. 586-603 
Por outro lado, sem o cultivo das virtudes, resultariam até mesmo inócuos aspectos ineludíveis de um ordenamento jurídico bem elaborado, como os requisitos mínimos estabelecidos para a convivência social, a força do dever prescrito pelas normas e os valores humanos que estas possam promover. As regras de colaboração social perdem a sua inteligibilidade e, consequentemente, têm a sua eficácia ameaçada se se restringem a proibir as condutas que a inviabilizam e a permitir que os cidadãos busquem aquilo que julgam ser os escopos mais importantes das suas vidas de maneira subjetivista, sem justificação racional; somente se essas regras de convivência se estendem às excelências da atividade humana - às virtudes - como escopos seus é que podem ser racionalmente defensáveis. Por sua vez, as prescrições normativas só possuem respaldo racional e recebem maior adesão por parte da cidadania se são vistas como uma propriedade das virtudes, isto é, como enunciados gerais e hipotéticos funcionais ao progresso ético individual e concreto dos seus destinatários; se, pelo contrário, estes só as percebem como ordens injustificadas ou, no melhor dos casos, como metas do comportamento humano às quais as virtudes estão finalizadas - a modo de anestésicos ante a dureza do cumprimento do dever -, a tendência é que sejam encarados como atos de violência - e, consequentemente, quando possível - dos quais é preciso esquivar-se. Finalmente, os valores éticos alentados pela lei jurídica são necessariamente reflexo de ações apreciáveis que se advertem nas vidas de pessoas reais, ou seja, de ações virtuosas; se ocorre um decréscimo no cultivo das virtudes em escala social, o conteúdo axiológico das normas legais tende a ser objeto de indiferença ou até mesmo de repugnância ${ }^{41}$.

Por fim, convém recordar que, no capítulo III da Política - onde trata do tema do governo do direito -, Aristóteles já sustentara uma doutrina similar. Ali escreve:

Todos os que se interessam pela boa legislação indagam acerca da virtude e da maldade cívicas. Desse modo, também é evidente que a cidade que o é verdadeiramente, e não só de nome, deve preocupar-se com a virtude; porque, se não, a comunidade transforma-se numa aliança $[\ldots]$ e a lei, num convênio; e como diz Licofrão o sofista, numa [mera] garantia dos direitos de uns e de outros, mas sem ser capaz de fazer que os cidadãos sejam bons e justos ${ }^{42}$.

Daqui se segue que, desde as suas próprias origens, a doutrina do governo da lei reconhece que ela é condição necessária do direito justo, mas nunca condição suficiente dele, pois deve ser complementada sinergicamente com a virtude dos governantes e dos cidadãos.

\section{GOVERNO DO DIREITO E DIREITOS HUMANOS}

Pois bem, existe uma questão complementar, que foi proposta várias vezes e que radica na pergunta sobre a necessidade ou desnecessidade da presença da ideia de direitos humanos como parte integrante do

\footnotetext{
${ }^{41}$ Cf. ABBÀ, Giuseppe. Costituzione epistemica della filosofia morale, op. cit., p. 95.

${ }^{42}$ ARISTÓTELES. Política, III, 9, 1280 b 5 ss.
} 
governo do direito ${ }^{43}$. Em outras palavras: para que se possa falar com propriedade de governo do direito, é preciso incorporar a noção de direitos humanos a este conceito ou isto seria um acréscimo apenas acidental e contingente? Dito de outro modo: embora pareça evidente que a vigência dos direitos humanos é um elemento integrante da justiça de um sistema jurídico, é-o também do conceito mesmo de governo do direito? Este último conceito pode ser formulado sem qualquer referência à noção de direitos humanos?

Quanto a isto, Martin Kriele sustenta a tese que pode ser chamada “inclusiva”, isto é, a que pressupõe uma continuidade conceitual entre governo do direito, democracia e direitos humanos. Escreve Kriele em Befraiung und politische Aufklärung:

A quintessência do iluminismo político [ ... e é a unidade de direitos humanos, divisão de poderes e democracia. A eficácia real dos direitos humanos pressupõe a sua validade jurídica, e esta, por sua vez, a divisão de poderes, porque a autoridade estatal só pode vincular-se aos direitos humanos quando está ligada ao direito [... ]. Assim [- conclui -], fecha-se o círculo: a divisão de poderes e a democracia têm a ideia dos direitos humanos como ponto de partida e de chegada. A tríade direitos humanos, divisão de poderes e democracia conforma uma unidade jurídico-institucional ${ }^{44}$.

Na sua Einführung in die Staatslehre, este mesmo autor afirma decisivamente que "a história dos direitos humanos e a do Estado constitucional formam uma unidade indivisível” 45 .

Por sua vez, o ideólogo pós-marxista argentino Ernesto Laclau sustenta a tese contrária, isto é, a da contingência estrita da vinculação entre as noções de direitos humanos e de estado democrático de direito. Com efeito, no seu já muito citado livro La razón populista, seguindo Chantal Mouffe, sustenta que:

Por um lado, temos a tradição liberal constituída pelo governo da lei, pela defesa dos direitos humanos e pelo respeito à liberdade individual. Por outro, a tradição democrática, cujas ideias principais são a da igualdade, da identidade entre governantes e governados e a da soberania popular. Não há uma relação necessária entre estas duas tradições diferentes, mas Mais adiante, precisa: apenas uma articulação histórica contingente ${ }^{46}$.

O fracasso da teoria democrática atual ao abordar a questão da cidadania é consequência do fato de que opera com uma concepção do sujeito que percebe os indivíduos como anteriores à sociedade, [e como] portadores de direitos humanos ${ }^{47}$.

1. Com relação a estas duas opiniões, cabe destacar antes de tudo que a argumentação efetuada por Kriele - fortemente atraente, à primeira vista - possui um caráter principalmente históricopragmático; isto é, baseia-se: na coexistência histórico-temporal das noções de governo do direito, de direitos humanos e de democracia;

\footnotetext{
${ }^{43}$ Cf. GRIFFIN, James. On human rights. Oxford: Oxford University Press, 2008, p. 242-251.

${ }^{44}$ KRIELE, Martin. Befreiung und politische Aufklärung. Freiburg: Verlag Herder, 1980. Cita-se conforme a versão castelhana de C. Gancho: Liberación e ilustración: defensa de los derechos humanos. Barcelona: Herder, 1982, p. 42.

${ }^{45}$ Idem. Einführung in die Staatslehre. Hamburg: Rowohlt Taschenbuch Verlag, 1975. Cita-se conforme a versão de E. Bulygin: Introducción a la teoría del Estado. Buenos Aires: Depalma, 1980, p. 159.

${ }^{46}$ LACLAU, Ernesto. La razón populista. México: FCE, 2011, p. 211.

${ }^{47}$ Ibidem, p. 212.
} 
2. E na conveniência dessa coincidência - que seria apenas contingente - para o bom funcionamento do sistema político mencionado e de cada um dos elementos que o integram. Mas, em lugar algum, o autor parece referir-se a algum tipo de explicação de caráter conceitual sobre o vínculo entre o governo do direito, a democracia e os direitos humanos. Certamente, os argumentos pragmáticos ou de utilidade têm um lugar na argumentação filosófico-prática; mas também é verdade que esse lugar é meramente acessório, e não pode suplantar ou substituir uma comprovação conceitual ou de implicação das noções ${ }^{48}$. Dito em outras palavras, Kriele não mostra a existência de uma implicação lógica entre os conceitos mencionados, mas apenas de uma contiguidade histórica que obteve bons resultados para o funcionamento do sistema político ocidental.

Quanto às teses de Laclau, é relevante pôr em evidência que ele defende de maneira definitiva o caráter meramente contingente da relação entre direitos humanos e democracia constitucional, isto é, a possibilidade de governos democráticos - que ele chama "populares" - sem a presença de direitos humanos. Ademais, para Laclau, isto seria algo desejável em princípio, uma vez que aquilo que ele assume como ideal em matéria política é o elemento democrático, entendido como política populista, que pode ter caráter hegemônico e até mesmo totalitário, sem que isso signifique uma desqualificação valorativa. "O fato de alguns movimentos populistas poderem ser totalitários [...] é certo, sem dúvida", escreve este autor, acrescentando que "a visão de Gramsci sobre a hegemonia $[\ldots]$ é, no entanto, profundamente democrática, porque implica a introdução de novos sujeitos coletivos na arena histórica" ${ }^{49}$. Pelo contrário, a ideia de direitos humanos tem um caráter intrinsecamente liberal-institucional, que, no discurso de Laclau, é um qualificativo claramente pejorativo ${ }^{50}$.

Pois bem, independentemente das opiniões destes autores, se se adota a visão jusnaturalista do governo do direito que se defendeu nas páginas precedentes, é manifesto que tanto o rule of law como os direitos humanos dependem constitutivamente da noção de direito natural e que se implicam reciprocamente. Isto porque tanto a supremacia do direito sobre o poder como a exigência de direitos subjetivos suprapositivos fazem parte dos requerimentos do direito natural, especialmente na sua versão clássico-realista ${ }^{51}$. Ademais, estes dois fatores implicam-se mutuamente, uma vez que a limitação constitutiva - não meramente formal - da autoridade estatal

\footnotetext{
${ }^{48}$ Veja-se TOULMIN, Stephen. Los usos de la argumentación. Trad. M. Morrás e V. Pineda. Barcelona: Península, 2007, p. 164170. Por sua vez, Ronald DWORKIN critica o uso da argumentação pragmática em várias partes do seu livro Justicia para erizos. Trad. H. Pons e G. Maurino. México: FCE, 2014, p. 399-403.

${ }^{49}$ LACLAU, op. cit., p. 209-212.

${ }^{50}$ Numa entrevista realizada por Amílcar Salas Oroño e outros, Laclau sustenta que "todo sistema social encontra-se polarizado entre dois extremos: o populismo, por um lado, e o institucionalismo, por outro. [...] quanto mais processos de mudança aconteçam, haverá maior predomínio do elemento populista, que é o que está a ocorrer na América Latina hoje em dia" (Entrevista con Ernesto Laclau. In: FREIBURN, Nicolás ET ALII (Comp.). Qué es el kirchnerismo? Buenos Aires: Continente, 201 1, p. 83. É preciso ter presente que, para Laclau, as expressões "mudança", "popular" e "populismo" possuem um caráter valorativo claramente positivo, de maneira que a alternativa "institucional” tem um conotação axiológica manifestamente negativa.

${ }^{51}$ Sobre esta versão, veja-se MASSINI CORREAS, Carlos Ignacio. Los derechos humanos en el pensamiento actual. Buenos Aires: Abeledo-Perrot, 1994, p. 143-167.
} 
pressupõe que os governados sejam titulares de direitos naturais - de direitos humanos, na nomenclatura contemporânea -, especialmente os de participação e de liberdade. Além destes, também são titulares dos direitos naturais de autonomia (sempre ordenada à realização de bens humanos básicos ${ }^{52}$ ) e de solidariedade, porque as normas de direito natural que os estabelecem são as mesmas que, do ponto de vista ético-jurídico, limitam o exercício do poder do governo político.

A vinculação constitutiva do rule of law com os direitos humanos também pode ser encontrada na noção de dignidade humana, pois - tal como Finnis desenvolveu acertadamente - tanto o rule of law como os direitos humanos justificam-se moralmente nessa noção. Com efeito, o governo do direito adquire o seu sentido radical à medida que torna possível que os homens sejam dirigidos e coordenados como agentes racionais dotados de dignidade ou valor intrínseco; tratar os sujeitos de direito como racionais e livres implica reconhecer neles, na prática, uma dignidade especial ${ }^{53}$. Quanto aos direitos humanos, está bastante difundida - e com boas razões - a ideia de que só seres dotados de uma dignidade intrínseca podem ser titulares de direitos cujo fundamento radical e decisivo é a sua própria realidade ontológica ${ }^{54}$. Assim, a dignidade humana acaba por outorgar sentido tanto ao rule of law como aos direitos humanos; e fá-lo de modo agregativo, isto é, incluindo os dois, sem que seja possível separá-los em conceitos independentes.

Deste modo, um poder político que não respeite os direitos humanos não poderá considerar-se propriamente como sujeito ao rule of law, uma vez que não atuará de acordo com o direito - natural, em princípio,

\footnotetext{
${ }^{52}$ A relação dos bens humanos básicos mais notória é a elaborada por John FINNIS, que a expôs pela primeira vez em Natural law and natural rights. Oxford: Oxford University Press, 1980, p. 91-99. Inspirado nesta obra e também em outras (concretamente, em GRISEZ, Germain. The way of the Lord Jesus: vol. 1 - Christian moral principles. Chicago: Franciscan Herald Press, 1983, p. 115140; GRISEZ, Germain; SHAW, Russel. Beyond the new morality: the responsabilities of freedom. Notre Dame - London: University of Notre Dame Press, 1980, p. 64-75; GRISEZ, Germain; BOYLE, Joseph; FINNIS, John. Practical principles, moral truth, and ultimate ends. The American Journal of Jurisprudence 32 (1987), p. 99-151), Giuseppe ABBÀ - no seu livro Felicidad, vida buena y virtud: ensayo de filosofía moral. Trad. Juan José García Norro. Barcelona: EIUNSA, 1992, p. 65-66 - distingue e elenca dez bens humanos básicos, divididos em quatro bens existenciais e seis bens experienciais. Os bens existenciais - isto é, "as atuações que consistem num exercício de vontade para superar qualquer conflito, pessoal ou interpessoal, e para realizar diferentes formas de harmonia" (p. 66) - são os seguintes:

1. "Harmonia com as outras pessoas, no grupo, na sociedade, na amizade";

2. "Harmonia consigo mesmo, entre a vontade, a razão e as paixões (paz interior)";

3. "Harmonia entre as próprias escolhas e o próprio comportamento (autenticidade ou coerência)"; e

4. "Harmonia com uma realidade sobre-humana que é princípio de valor e de significado para o mundo e para o homem".
} Por sua vez, os bens experienciais - que "são as atuações que, apesar de poder ser causadas pela livre escolha, não consistem, em si mesmas, no exercício da vontade livre, mas no exercício de faculdades diferentes da vontade” (p.65) - são estes:

1. "A vida, que é preciso manter e cuidar ou procriar e educar";

2. "O conhecimento de todo tipo";

3. "A experiência do belo";

4. "O jogo";

5. "A arte"; e

6. "O trabalho".

${ }^{53}$ Cf. FINNIS, John. Natural law and natural rights. Oxford: Oxford University Press, 201 1, p. 272.

${ }^{54}$ Cf. FINNIS, John. Aquinas: Moral, political, and legal theory. Oxford: Oxford University Press, 1998, pp. 176-180. No seu livro The heart of human rights (Oxford: Oxford University Press, 2013, p. 98 et seq.) Allen BUCHANAN também fundamenta os direitos humanos na dignidade humana, embora a partir de outra perspectiva teórica. 
e, de modo acidental, positivo - que estabelece os direitos naturais do homem e porque não respeitará a sua dignidade inerente.

Evidentemente, se se adota a versão do governo do direito meramente formal do Rechtsstaat alemão do século XIX ${ }^{55}$, de matriz expressamente positivista, o reconhecimento dos direitos humanos não integrará essencialmente o conceito de governo do direito. Com efeito, "[s]e o direito pode ser reduzido aos simples comandos daqueles que ocupam o poder, então o Rechtsstaat torna-se um instrumento de opressão e o direito torna-se uma arma, como a faca, que pode ser empunhada para o bem ou para a desgraça por aqueles que a têm nas mãos" ${ }^{56}$. Na concepção oitocentista de Estado de direito, prevaleceu a preocupação instrumental de transformar o direito numa técnica de solução dos conflitos a serviço da vontade soberana, de maneira a satisfazer os desejos de segurança e certeza no ordenamento jurídico. Assim, terminou-se por encerrar o Estado numa neutralidade axiológica que desembocou no formalismo, o qual, por sua vez, mostrou-se incapaz de produzir valores verdadeiramente unificadores, como o são os direitos humanos ${ }^{57}$.

Para sermos mais precisos, deve-se esclarecer que, nessa época, uma noção aparentada com a de direitos humanos também era objeto de apreço dentro do universo jurídico. Tratava-se da noção dos direitos naturais individualistas, formulada detalhadamente pelos integrantes do jusnaturalismo racionalista do século XVIII e que, no princípio do XIX, já triunfara nos terrenos político e legislativo, máxime por força do movimento da codificação, que, entre outras finalidades, pretendeu a inserção plena de uma concepção abstrata do direito natural na concretude das leis positivas. Com essa vitória já assegurada, os esforços teóricos e práticos de grande parte dos juristas europeus concentraram-se no desenvolvimento do método da ciência do direito positivamente vigente, que era reputado como a forma exclusiva de conceber-se o direito ${ }^{58}$.

Por causa destas razões e daquilo que se viu precedentemente neste trabalho, a versão de governo do direito do Rechtsstaaté uma instância degradada e, em suma, falida do conceito de rule of law. Portanto, a opção integral e consistente é recepcionar o que Brian Tamanaha denomina uma "teoria substantiva" ${ }^{9}$ do governo do direito, que inclua conceitualmente a dimensão dos direitos humanos. Dito brevemente: não há estado de direito integral sem a inclusão dos direitos humanos no seu próprio conceito.

\footnotetext{
${ }^{55}$ Veja-se KRIELE. Introducción a la teoría del Estado, op. cit., p. 146-149.

${ }^{56}$ SELLERS, Mortimer. An introduction to the rule of law in comparative perspective. In: SELLERS, Mortimer; TOMASZEWSKI,

Tadeusz (Eds.). The rule of law in comparative perspective. New York: Springer, 2010, p. 3.

${ }^{57}$ Cf. VIOLA, Francesco; ZACCARIA, Giuseppe. Le ragioni del diritto. Bologna: Il Mulino, 2003, p. 181

${ }^{58}$ Cf. FASSÒ, Guido. Storia della filosofia del diritto: vol. III - Ottocento e novecento. $5^{\mathrm{a}}$ ed. aggiornata a cura di Carla Faralli. Bari: Laterza, 2009, p. 5 .

${ }^{59}$ TAMANAHA, p. 102 ss.
} 
Evidentemente, o acento que se pôs na argumentação conceitual não implica de maneira alguma que se deixe de lado o discurso pragmático ou consequencial - ainda que não consequencialista ${ }^{60}$-, que possui valor especial no discurso prático. Neste sentido, só se pode aderir às disquisições efetuadas neste sentido por Martin Kriele, segundo as quais o governo do direito é o âmbito adequado para a vigência dos direitos humanos e para a práxis democrática. Também é certo que, contrariamente ao que Laclau sustenta, fora de um sistema de rule of law é muito difícil - quase impossível - o funcionamento efetivo de um regime democrático que mereça este nome. Assim, estes argumentos de utilidade prática vêm a somar-se aos de caráter conceitual, e não a excluí-los; por outro lado, é preciso reconhecer que, na filosofia prática, a argumentação acerca das consequências de ações e de instituições possui uma força retórica especial, que não deve ser deixada de lado.

\section{CONCLUSÃO: O GOVERNO DO DIREITO, AS VIRTUDES MORAIS E OS DIREITOS HUMANOS}

Do que se expôs sucintamente até agora, é possível extrair, pelo menos, as seguintes conclusões:

1. A ideia do governo do direito não se reduz a uma das suas várias concreções históricas, a liberaliluminista ${ }^{61}$, mas tem uma origem muito anterior e muito diversa no pensamento grego e romano clássico, bem como nas melhores versões do pensamento medieval. Estas versões compõem uma tradição de pensamento e de investigação mais rica, realista e matizada que a proposta pelos iluministas nos anos que precederam a revolução francesa;

2. Tomás de Aquino desenvolve esta ideia de maneira completa e sistemática, tanto do ponto de vista formal e dos procedimentos como da perspectiva dos conteúdos jurídicos. Nesse desenvolvimento, a ideia do governo do direito encontra-se fundamentada principalmente na doutrina da lei - ou direito natural, de modo a possuir um caráter eminentemente jusnaturalista;

3. Além disto, essa versão da ideia do governo do direito complementa-se - tanto na sistemática de Aristóteles como na de Tomás de Aquino - com a de uma ética das virtudes, que são as que tornam possíveis - enquanto princípios internos - tanto a especificação como a implementação do governo eminente das leis - normas e princípios - jurídicas ou direito normativo. Pelo contrário, a versão proposta pelos liberais deixa de lado as virtudes morais e centra-se em artifícios meramente institucionais, como a divisão tripartite dos poderes do Estado;

4. Por outro lado, a versão de governo do direito proposta, de caráter inegavelmente jusnaturalista, integrase à ideia de direitos humanos, uma vez que estes fazem parte constitutiva do direito que o governo

\footnotetext{
${ }^{60}$ Sobre o "consequencialismo" moral, veja-se MASSINI CORREAS, Carlos Ignacio. Sobre ética y filosofía analítica: Elizabeth Anscombe y la filosofía moral moderna. Mendoza: Opúsculo Filosófico - CEFIC, 2015, passim.

${ }^{61}$ Entre outros autores, Ernesto LACLAU discute esta versão em La razón populista, op. cit., p. 207 et seq. vol.09, nº. 01, Rio de Janeiro, 2016.pp. 586-603
} 
político deve respeitar e justificam-se na própria ideia de dignidade humana. Assim, a vinculação entre o rule of law e os direitos humanos - que foi questionada várias vezes - mostra-se integrativa conceitual e intrinsecamente.

5. Por fim, especialmente em face dos diversos e reiterados ataques de que a ideia de governo do direito tem sido objeto recentemente - por parte das escolas pós-marxistas, da Análise Econômica do Direito, do utilitarismo tradicional ou renovado e de alternativas ideológicas -, convém pôr em evidência a necessidade de renovação, reformulação e atualização da tradição clássica do governo do direito, como uma alternativa valiosa ante aqueles que pretendem substituí-la por um decisionismo populista, por uma mera crítica nilista, por um autonomismo tendencialmente anárquico ou por um mero instrumentalismo vazio de conteúdos éticos.

\title{
NOTES ON THE GOVERNMENT OF THE RIGHT, ETHICS THE VIRTUES AND HUMAN RIGHTS
}

\begin{abstract}
In this paper the signification and origins of the idea of rule of law are summarized, distinguishing its classical sense from that illuminist and binding it - what appears to be necessary - with virtue ethics and to the notion of human rights. Thereby, the complete formula of common good - of general justice - will root in the supremacy of law, which is that of practical-ethical reason, along with the presence of moral virtues both in rulers and subjects, as well as the respect for the natural rights of human beings.
\end{abstract}

Keywords: rule of law - virtue ethics - human rights.

\section{BIBLIOGRAFIA}

ABBÀ, Giuseppe. Costituzione epistemica della filosofia morale: ricerche di filosofia morale - 2. LAS: Roma, 2009 Felicidad, vida buena y virtud: ensayo de filosofía moral. Trad. Juan José García Norro. Barcelona: EIUNSA, 1992

Lex et virtus: studi sull'evoluzione della dottrina morale di san Tommaso d'Aquino. Roma: LAS, 1983

Quale impostazione per la filosofia morale? Ricerche di filosofia morale - 1. Roma: LAS, 1996

\section{ARISTÓTELES. Política}

BRANCTON, Henry. On the laws and customs of England. Vol. III. Cambridge (Mass.): Harvard University Press, 1968

BUCHANAN, Allen. The heart of human rights. Oxford: Oxford University Press, 2013 
CASTAÑO, Sergio Raúl. Brève analyse de l'empire de la loi chez Aristote. Archiv für Rechts-und Sozialphilosophie, vol. 83-4, Stuttgart, 1997, pp. 548-554

CÍCERO.A república

As leis

D’AGOSTINO, Francesco. Lo Stato di diritto: dimensioni e problemi. In: IDEM. Filosofia del diritto. $3^{\text {a }}$ ed. ampliata. Torino: Giappicchelli, 2000

DWORKIN, Ronald. Justicia para erizos. Trad. H. Pons e G. Maurino. México: FCE, 2014

FASSÒ, Guido. Storia della filosofia del diritto. Vol. III: Ottocento e novecento. $5^{\mathrm{a}}$ ed. aggiornata a cura di Carla Faralli. Bari: Laterza, 2009

FINNIS, John. Aquinas: moral, political, and legal theory. Oxford: Oxford University Press, 1998

Aquinas' moral, political and legal philosophy. In: ZALTA, Edward N. (Ed.). The Stanford encyclopedia

of philosophy. Fall 2011 edition. Disponível em: plato.stanford.edu/archives/fall 2011/entries/aquinas-moralpolitical (acesso em 18 de junho de 2014)

Natural law and natural rights. Oxford: Oxford University Press, 2011

GARCÍA PELAYO, Manuel. Derecho Constitucional Comparado. Madrid: Revista de Occidente, 1964

GARCÍA-HUIDOBRO, Joaquín. Razón práctica y derecho natural: el iusnaturalismo de Tomás de Aquino. Valparaíso: Edeval, 1993

GEORGE, Robert P. Making men moral: civil liberties and public morality. Oxford: Clarendon Press, 1995

GRIFFIN, James. On human rights. Oxford: Oxford University Press, 2008

ISIDORO DE SEVILLA. Etimologías. Ed. crítica bilíngue de J. Oroz Reta e M. A. Marcos Casquero Madrid: BAC, 1982, t. I

JOHNSON, Curtis N. Aristotle's theory of the state. London: MacMillan, 1990

KELSEN, Hans. Teoría pura del derecho. 8a ed. Trad. R. Vernengo. México: Porrúa, 1995

KRAUT, Richard. Aristotle. Political Philosophy. Oxford: Oxford University Press, 2002

KRIELE, Martin. Introducción a la teoría del Estado. Trad. E. Bulygin. Buenos Aires: Depalma, 1980

Liberación e ilustración: defensa de los derechos humanos. Trad. C. Gancho. Barcelona: Herder, 1982

LACLAU, Ernesto. La razón populista. México: FCE, 2011

LETWIN, Robin. On the history of the Idea of law. Cambridge: Cambridge University Press, 2008

LLANO, Carlos. Sobre la idea práctica. Pamplona: EUNSA, 2007 
MASSINI CORREAS, Carlos Ignacio. Filosofia del derecho: tomo I - El derecho, los derechos humanos y el derecho natural. Buenos Aires: LexisNexis - Abeledo Perrot, 2005

Los derechos humanos en el pensamiento actual. Buenos Aires: Abeledo-Perrot, 1994

Sobre ciencia práctica y prudentia. Aproximaciones desde las ideas de John Finnis. Sapientia, n. 227-228, Buenos Aires, 2010, pp. 41-53

Sobre ética y filosofía analítica: Elizabeth Anscombe y la filosofía moral moderna. Mendoza: Opúsculo Filosófico - CEFIC, 2015

MORAIS, José Luis Bolzan de. Estado de direito. In: BARRETTO, Vicente de Paulo; CULLETON, Alfredo (Coords.). Dicionário de filosofia política. São Leopoldo: UNISINOS, 2010, pp. 186-189.

PIEPER, Joseph. Las virtudes fundamentales. Madrid - Bogotá: Rialp - Quinto Centenario, 1998

PLATÓN. Las leyes. Trad.J. M. Pabón e M. Fernández-Galiano. Madrid: Instituto de Estudios Políticos, 1960

POLO, Leonardo. Lecciones de ética. Pamplona: EUNSA, 2013

PORTER, Jean. The recovery of virtue: the relevance of Aquinas for Christian ethics. London: SPCK, 1990

ROHNHEIMER, Martin. La perspectiva de la moral: Fundamentos de la ética filosófica. Madrid: Rialp, 2000

SALAS OROÑO, Amílcar ET ALII. Entrevista con Ernesto Laclau. In: FREIBURN, Nicolás ET ALII (Comp.). Qué es el kirchnerismo? Buenos Aires: Continente, 2011

SANTOS, Mário Ferreira dos. Ontologia e cosmologia. São Paulo: Logos, 1957

SELLERS, Mortimer. An introduction to the rule of law in comparative perspective. In: SELLERS, Mortimer; TOMASZEWSKI, Tadeusz (Eds.). The rule of law in comparative perspective. New York: Springer, 2010, p. 1-9.

SOLUM, Lawrence B.; FARRELLY, Colin (Eds.). Virtue jurisprudence. New York: Palgrave-MacMillan, 2011

STRAUSS, Leo. Sobre la tiranía. Trad. L. Rodríguez Duplá. Madrid: Encuentro, 2005

TAMANAHA, Brian. On the rule of Law: history, politics, theory. New York: Cambridge University Press, 2009

TOMÁS DE AQUINO. Quaestio disputata de virtutibus in communi. Trad. Laura Corso de Estrada. Pamplona: EUNSA, 2000

Summa theologiae

TOULMIN, Stephen. Los usos de la argumentación. Trad. M. Morrás e V. Pineda. Barcelona: Península, 2007

VANOSSI, Jorge. Estado de Derecho. Buenos Aires: Astrea, 2008

VIOLA, Francesco. Legge umana, rule of lawed etica delle virtù in Tommaso d'Aquino. In: MANGINI, Michele; VIOLA, Francesco. Diritto natural e liberalismo: dialogo o conflitto? Torino: Giappicchelli, 2009

VIOLA, Francesco; ZACCARIA, Giuseppe. Le ragioni del diritto. Bologna: Il Mulino, 2003 
Trabalho enviado em 23 de janeiro de 2016. Aceito em 05 de fevereiro de 2016. 